\title{
Política de Habitação de Interesse Social no recorte da segregação socioespacial e os efeitos da violência social
}

\author{
Clarete Trzcinski ${ }^{1}$ \\ Augusto Jobim do Amaral ${ }^{2}$
}

\begin{abstract}
Resumo: O Brasil é marcado por históricas e profundas desigualdades sociais, onde o fenômeno da violência é um constante insofismável, em especial desde o recorte da segregação sócio-espacial. Neste sentido, o estudo tem por objetivo analisar, desde o aporte das políticas de habitação no município de Chapecó/SC, os efeitos de violência social operados a partir da segregação sócio-espacial. Para tanto, como procedimento técnico para a coleta de dados, foi utilizado um formulário para o adequado levantamento das informações, tendo como base uma entrevista semi-estruturada, com 9 (nove) moradores do "Loteamento Expoente", em visitas domiciliares, acompanhadas pelas agentes comunitárias que aleatoriamente definiam as famílias respondentes. A pesquisa teve enfoque qualitativo, e os dados foram analisados e interpretados a partir da técnica de análise de conteúdo. Os resultados mostram que, na visão dos moradores, a violência é um problema bastante grave no Loteamento, em suas mais diversas manifestações, v.g. a violência doméstica e intrafamiliar; violência de gênero, violência institucional, além dos vandalismos, delinquência, marginalidade, crimes de mortes, assaltos que são decorrentes da violência da ordem social, decorrentes do precário processo de urbanização. Concluise, que a proliferação da violência e da insegurança é fruto das condições desfavoráveis em que se encontra grande parte da população. A política de habitação social, ofertada vai além do direito a uma casa, mas inclui a efetivação do desenvolvimento social, econômico e cultural de seus moradores.
\end{abstract}

Palavras chave: Habitação de Interesse Social. Segregação sócio-espacial; Violência.

Abstract: Brazil is characterized by historical and deep social inequalities, where the phenomenon of violence is an unmistakable constant, in particular since the cutting of socio-spatial segregation. In this sense, the study aims to analyze, from the contribution of housing policies in the municipality of Chapecó/SC, the effects of social violence operated from socio-spatial segregation. In order to do this, as a technical procedure for data collection, it was used a formulary for the adequate information collection, based on a structured interview, with 9 (nine) residents of the "Expoente Allotment", at home visits, accompanied by community agents which randomly defined the respondent families. The research had a qualitative focus, and the data were analyzed and interpreted from the content analysis technique. The results show that, in the view of the residents, the violence is a serious problem in the Allotment, in its most diverse manifestations, e.g. domestic and intrafamily violence; gender violence, institutional violence, besides to vandalism, delinquency, marginality, crimes of death, robberies that are due to the violence of the social order, resulting from the precarious urbanization process. It is concluded that, from the community demands, an emphasis on the need to build a police station in the Allotment.

Keywords: Social Housing Interest. Socio-spatial segregation. Violence.

\footnotetext{
${ }^{1}$ Doutora em Engenharia de Produção da UfRGS. Professora do Programa de Pós-Graduação em Políticas Sociais e Dinâmicas Regionais (Mestrado) da Unochapecó. clarete@unochapeco.edu.br

2 Doutor em Altos Estudos Contemporâneos (Ciência Política, História das Ideias e Estudos Internacionais Comparativos) pela Universidade de Coimbra (Portugal). Professor do Programa de Pós-Graduação em Ciências Criminais (PPGCCrim/mestrado e doutorado) da Pontifícia Universidade Católica do Rio Grande do Sul (PUCRS). guto_jobim@hotmail.com
} 


\section{Introdução}

A urbanização sob a ótica da sociedade industrial pela urbana, é analisada por Lefebvre, quando aponta que poder gozar o ambiente urbano em liberdade é um privilégio, um direito, e Harvey (2012) destaca o direito à cidade como direito humano. Para Lefebvre (2001, p. 118) o direito à cidade "não pode ser concebido como um simples direito de visita ou de retorno às cidades tradicionais. Só pode ser formulado como direito à vida urbana, transformada, renovada".

Harvey reporta-se ao Robert Park para conceituar cidade, como sendo "a tentativa mais bem-sucedida do homem de reconstruir o mundo em que vive o mais próximo do seu desejo". Mas, se "a cidade é o mundo que o homem criou, doravante ela é o mundo onde ele está condenado a viver". Assim, indiretamente, e sem qualquer percepção clara da natureza da sua tarefa, ao construir a cidade o homem reconstruiu a si mesmo. $(1967$, p.3, apud HARVEI, 2012).

Ao longo do século XX, mas, sobretudo nos períodos mais recentes, o processo de urbanização brasileiro vincula-se de forma crescente com o da pobreza, cujo locus passa a ser, cada vez mais, a cidade, particularmente a grande cidade. O campo e a agricultura moderna repelem os pobres, e os trabalhadores da agricultura capitalizada, do agronegócio, vivem cada vez mais nos espaços urbanos. A reforma agrária, que poderia neutralizar a migração e concentração urbana, continua sem acontecer. A indústria se desenvolve com a incorporação de novas tecnologias e a escassa criação (e muitas vezes destruição) de empregos, e o terciário associa formas modernas a formas primitivas que remuneram muito mal e não garantem o emprego. (MEDEIROS, 2013).

Desde os anos de 1970, a sociologia brasileira tem analisado intensamente a pobreza urbana. Essa pobreza urbana não é só uma questão de nível, ou índice, mas também de concentração espacial e social, envolvendo desigualdade, separação e homogeneidade espacial. Esse problema também está ligado às políticas públicas, que deveriam ser criadas para melhorar a situação da população. O problema não é novo, nas cidades brasileiras a ênfase da literatura sempre esteve na existência de desigualdades e injustiças na distribuição da renda e dos serviços públicos do que na separação dos grupos sociais. (TORRES, et al., 2003). 
O propósito do artigo é mostrar a partir da análise de experiências de violência, e da reprodução de desigualdade social e de segregação sócio espacial que vivenciam os moradores do Loteamento Expoente, localizado na cidade de Chapecó, e primeiro empreendimento construído com recursos do Programa Minha Casa Minha Vida; a violência ser um fenômeno bastante difundido, expressando a concepção dos moradores do Loteamento.

Trata-se de um estudo empírico de uma área específica, embora pudesse ter realizado entrevistas com outros Loteamentos de Interesse Social, decidiu-se na concentração de apenas uma área, ocupada por pessoas definidas pelo PMCMV com renda de até 3 salários mínimos, podendo assim interpretá-las em seu espaço de vivência e até confirmar as experiências de medo e violência divulgadas pela mídia.

Parte-se do aporte teórico das políticas habitacionais no Brasil, em seus aspectos social, econômico e político, adentrando nas questões urbanas e da questão social manifestada através da precariedade do trabalho e do enfraquecimento do Estado de BemEstar-Social que gerou pobreza e ampliação das desigualdades econômico, social e territorial além da violência e da insegurança.

\section{Habitação de interesse social no Brasil}

A habitação popular só foi assumida como uma expressão da questão social, a partir de 1964, período em que foi considerado marcante a presença do Estado, que implementou a política através do Sistema Financeiro de Habitação. Porém o sistema foi considerado ineficaz, por não atingir a população de mais baixa renda, foco principal de sua existência; por inadimplência e redução drástica da captação de recursos, aliada a combinação de uma conjuntura recessiva, entra numa profunda crise, sendo extinto em 1986.

Na década de 1970, a crise fiscal da sociedade salarial levou o desenho e a imposição de políticas econômicas neoliberais e o desmantelamento do estado de BemEstar-Social. Isso afetou profundamente a coesão social, quando situações de precariedade se generalizaram e informalidade do trabalho, deixando um número crescente de trabalhadores desprotegidos, aumentando os altos níveis de pobreza e desigualdade. A partir deste momento se criam novos modelos de Seguridade Social que sustentam o Estado 
de Bem-Estar- Social assumindo diferentes modalidades nos países europeus. Um modelo que nunca se desenvolveu plenamente na América Latina. (ZICCARD, 2016)

A pobreza urbana é reflexo da questão social devido a falta de um Estado de BemEstar-Social e, sobretudo, dos baixos salários que exclui a população da estrutura social.

Para Castel $(1995$, p.18) a questão social é um desafio, porque é através dela que a sociedade "experimenta o enigma de sua coesão e tenta conjurar o risco de sua fratura". Para o autor a questão social é, na verdade, as ações públicas, disponibilizadas pelo Estado, na perspectiva de garantir a sobrevivência social dos cidadãos. Ou seja, quando o Estado assume a questão social enquanto problema estrutural, surge a mediação instrumentalizada pelas políticas sociais.

Nessa ótica lamamoto (2001) aponta que a gênese da questão social, foi fundada num tipo de relação social determinante e própria da sociedade capitalista, na qual a riqueza produzida por toda a sociedade é apropriada privadamente, e de seu desenvolvimento na contemporaneidade, como "expressão de desigualdades econômicas, políticas e culturais das classes sociais, mediatizadas por disparidades nas relações de gênero, características ético-raciais e formações regionais, colocando em causa amplos segmentos da sociedade civil no acesso aos bens da civilização" (p.17).

Nesse sentido, a questão social é desencadeada pelas más condições de vida que prevalece nas cidades e pode-se dizer que a questão urbana é uma consequência da questão social, porque é no espaço urbano que se reproduz a força de trabalho, nela se localiza a produção, a fábrica e a habitação; e na sociedade global é o espaço onde localizam as atividades do setor moderno da economia, financeiras, bancarias e de informatização (ZICCARDI, 2016).

Marx e Engels (1985) analisam criticamente o sistema capitalista e a luta de classes, a partir da burguesia, que detém os meios de produção e o proletariado, que vende sua força de trabalho em troca de um salário. Seu resultado é que essas relações seriam determinadas, na sociedade capitalista através dos mios de produção material.

Com o processo de democratização, em 1988, através da Constituição Federal, a política habitacional é identificada pelo Estado, forçado pela pressão popular de garantir a moradia digna como um direito do cidadão. 
Desde a extinção do BNH em 1986, visualiza-se uma lacuna até 2003, conjuntura em que foi criado o Ministério das Cidades, como órgão gestor do SNHIS; em 2004 foi aprovada a Nova Política de Habitação, que ficou alinhada ao disposto na Constituição Federal de 1988, e ao Estatuto da Cidade, buscando avançar em relação a função social da propriedade, da questão da habitação como questão do Estado e direito do cidadão; em 2005 foi instituído a Lei 11.124. São avanços importantes, os quais demonstram um direcionamento de aplicação de recursos na área habitacional, voltado para famílias com renda mensal abaixo de cinco salários mínimos. Entretanto, o direito a moradia digna, com infraestrutura adequada não é garantindo a todos em nosso país.

Nestes avanços, direciona-se para a questão da descentralização das ações, através da gestão compartilhada, e direcionando responsabilidades nas três esferas de governo. Portanto, a gestão da habitação é acompanhada e avaliada tanto pelo poder público quanto pela sociedade civil, igualmente representada nos Conselhos de Habitação. Esse controle social consolida um modelo de gestão transparente em relação às estratégias, a execução e a avaliação da política. Porém, a implementação da descentralização na área da habitação, é bastante recente, e muito se tem para avançar neste sentido. A política de habitação para se consolidar em nível municipal necessita de condições de infra-estrutura, maior eficiência na administração dos recursos públicos, capacidade de organização política dos conselhos, bem como da expansão da oferta de moradia para a população de baixa renda.

A partir de 2007, novas mudanças ocorreram no que tange à forma de se implantar políticas habitacionais no Brasil. Visando reverter esse quadro, o país vem se organizando para retomar o Planejamento do setor habitacional, que não ocorre desde a extinção do Banco Nacional de Habitação, através do discurso do crescimento da economia.

$\mathrm{Na}$ área habitacional, o governo da época passa a liberar recursos para o investimento habitacional por meio do Fundo Nacional de Habitação de Interesse Social (FNHIS) lançando o Plano de Aceleração do Crescimento (PAC), destinado a promover o crescimento econômico com um ambicioso programa de investimentos em infraestrutura (ARAGÃO, 2012). Entretanto, tem-se que levar em consideração que o crescimento econômico é de vital importância para o país, mas tem que ter sustentação social e ambiental. 
Com base em Rolnik (2015), em 2008, começou-se a elaborar um pacote habitacional, nos moldes do modelo chileno, por meio de subsídio direto ao comprador. $\mathrm{O}$ pacote foi batizado como Programa Minha Casa Minha Vida (MCMV), lançado em março de 2009. A base inicial do programa era atender apenas as regiões metropolitanas e cidades com mais de 100 mil habitantes, áreas de atuação do segmento econômico das incorporadoras. Pressionado, o governo teve que estender o programa para cidades com menos de 50 mil habitantes. O Programa foi um verdadeiro sucesso, pois a partir de 2010, cerca de 1 milhão de unidades financiadas pelo FGTS e SBPE foram lançadas por ano, 4 vezes maior do que em 2003. Em 2014 o programa havia contratado 3,5 milhões de unidades e entregado cerca de 1,7 milhão de casas e ou apartamentos. Portanto, se de um lado o programa foi desenhado para incentivar empresas privadas a se comprometerem com a produção de habitação para moradores de baixa renda, por outro lado, permaneceu dependente de recursos públicos, mobilizados para subsidiar a aquisição da propriedade por compradores de baixa e média renda. Esse arranjo financeiro implicou a transferência de riscos para as instituições públicas, ao mesmo tempo em que manteve os lucros com agentes privados, reiterando os padrões históricos de apropriação de fundos públicos por atores privados no país.

Maricato (2006) relata que no Brasil o mercado privado oferece um produto de luxo que abrange menos de $30 \%$ da população e que a classe média tem se apropriado dos recursos subsidiados utilizados na promoção pública de moradias, deixando a população de baixa renda sem alternativas. Resultante desse quadro, o déficit habitacional está concentrado nas faixas de renda mais baixas: 92\% está situado entre 0 e 5 salários mínimos e $84 \%$ entre 0 e 3 salários mínimos.

Este déficit habitacional é resultante de falta de alternativas habitacionais, gerada pelo intenso processo de urbanização, baixa renda das famílias, apropriação especulativa de terra urbanizada e inadequação das políticas de habitação; o que levou uma parcela significativa da população a viver em assentamentos precários e informais. Estes se caracterizam pela informalidade na posse da terra, ausência ou insuficiência de infraestrutura, irregularidade no processo de ordenamento urbano, falta de acesso serviços e moradias com graves problemas de habitabilidade, construídas pelos próprios moradores sem apoio técnico e institucional (MINISTÉRIO DAS CIDADES/PlanHab, 2009). 
O fato é que a habitação historicamente sempre se posicionou a margem da concepção de direito, por não atingir a parcela da população com menor renda. Pois, as desigualdades sociais e a concentração de renda, são características da sociedade brasileira, e se manifestam fisicamente nos espaços segregados das cidades. Nelas, as carências habitacionais constituem, talvez, o maior problema: a falta de moradia digna para população mais carente, que responde por 92\% do déficit habitacional brasileiro (BRASIL, 2004).

Diante disso, visualiza-se em termos de Política Habitacional no Brasil, que ela tem sido pautada pela insuficiência, precariedade, exclusão, sendo que os modelos adotados têm se revelado insuficientes e inadequados. Corrobora Maricato $(2009$, p. 34) quando aponta que "se revelaram incapazes de sanar a carência das camadas mais pobres da população".

A segregação socioespacial na ótica apresentada é produto de um processo de "urbanização à brasileira", que perpetuou a manutenção dos conflitos socioeconômicos, principalmente no acesso â aquisição da terra, e intensificou a periferização da cidade ao permitir a implantação de conjuntos habitacionais de interesse social em locais com pouco ou nenhuma infraestrutura consolidada.

Discutir a violência na ótica do urbano se faz necessário compreender seu significado.

\section{Procedimentos metodológicos}

A metodologia adotada foi predominantemente qualitativa, uma vez que se analisou os dados coletados de modo a descrever as percepções e os significados referentes a concepção de violência de moradores do Loteamento Expoente. A pesquisa qualitativa para Flick (2009, p.20) possui grande "relevância ao estudo das relações sociais devido a pluralização das esferas da vida".

Quanto aos procedimentos técnicos para a coleta de dados, foi utilizado o formulário para o levantamento das informações. A escolha pelo formulário aconteceu pelo fato de o entrevistador preencher o mesmo (BARROS; LEHFELD, 2001). A aplicação deste instrumento se deu através da aplicação da técnica da entrevista semi-estruturada, com questões abertas e fechadas em visitas domiciliares, mediante assinatura do termo de livre esclarecimento e consentimento, conforme determina a resolução 466/2012. 
Os sujeitos envolvidos na pesquisa são moradores do Loteamento Expoente selecionados aleatoriamente que totalizaram nove (9) sujeitos. Haja vista que, ao contabilizar esse numero, identificou-se que as respostas eram todas no mesmo sentido, o que levou-nos a priorizar os dados coletados.

As entrevistas foram feitas juntamente com as Agentes de Saúde, após dois contatos com a Coordenadora do Posto de Saúde que sugeriu o acompanhamento das profissionais, pelo fato delas possuírem uma proximidade maior com a comunidade, facilitando o acesso aos entrevistados. Ou seja, duas Agentes de Saúde nos direcionava para os moradores "possíveis respondentes", pessoas que elas conhecem e que estavam em casa no momento da visita e que aceitassem ser entrevistados.

Diante das constantes ameaças de traficantes e da reintegração de posse que aconteceu no mesmo mês da visita, consideramos importante a presença das Agentes de Saúde para que fosse possível conquistar a confiança dos moradores, tendo em vista a participação na pesquisa. Assim mesmo, três (3) moradoras decidiram não realizar a entrevista. Haja vista que os boatos que correm lá, é de que 'ninguém ouve e nada vê'. Corroborando com a realidade vivida pelos moradores, foi bem visível o medo deles de falarem sobre as situações de violência presenciada, o que nos levou a diversas explicações de que as entrevistas não tinham relação com denuncia e que seus nomes seriam mantidos no anonimato.

Para analisar o material textual, utilizou-se a análise de conteúdo, de acordo com Bardin (2011) absorve o investigador pelo escondido, o latente, o não aparente, o não dito, repetido por qualquer mensagem.

\section{Resultados e discussões}

41 A política habitacional no município: e as formas de segregação sócio-espacial

A análise sobre o aporte das políticas públicas de habitação de interesse social no Brasil remete para o fenômeno de central importância, que é a marginalização das condições de vida de massivos setores sociais que não podem se inserir completamente no sistema produtivo e que recebem formas de habitação precária como é o caso de cidades brasileiras. 
Chapecó, está localizada no Oeste do Estado de Santa Catarina, com a intenção de iniciar a erradicação da habitação em áreas irregulares, foi entregue em 2011, o Conjunto Habitacional Expoente. Construído com recursos do Programa do Governo Federal, mediante uma parceria entre a Caixa Econômica Federal e a Prefeitura de Chapecó, autorizado em outubro de 2009, no mesmo mês a Construtora Embracol firmou o contrato de construção do loteamento junto a Caixa Econômica Federal. Trata-se do maior empreendimento habitacional no oeste catarinense, construído em uma área de 82 mil metros quadrados, com um total de 470 moradias. O investimento total no projeto é de R\$ 20,6 milhões. O empreendimento foi entregue em prazo extraordinário de pouco mais de 14 meses.

Do total de 470 moradias, 336 são apartamentos de 45 metros quadrados e 134 são casas de 36 metros quadrados, contendo dois quartos, sala, cozinha e banheiro. Destas, 15 estão adaptadas para pessoas com deficiência e 15 para idosos. O Loteamento está dividido em Expoente 1, 2, 3 e 4. O Expoente 1 tem 13 blocos de apartamentos, o Expoente 2 possui 15 blocos, o Expoente 3 tem 8 blocos e o Expoente 4 foi composto por 6 blocos. Cada bloco tem 2 andares e cada andar possui 4 apartamentos. Localiza-se o "Loteamento Expoente" no bairro Seminário (HETZEL, 2016).

A escolha dos beneficiados pelo programa foi feita por meio de sorteio, levando em consideração alguns critérios de seleção. Num primeiro momento, a prefeitura identificou os interessados. Entre 18 de maio a 30 de outubro de 2009, através da Secretaria de Habitação, distribuíram-se 7.588 senhas para famílias. Nesse período, foram feitos 2.618 cadastros, posteriormente avaliados considerando critérios como baixa renda, estarem estabelecidas em áreas do risco, mulheres chefes de família, ou seja, aquelas famílias que estavam em situações de risco e de vulnerabilidade social. (HETZEL, 2016).

Os critérios estabelecidos pelos Programas de Habitação Social demonstra que a segregação socioespacial, em Chapecó, ocorre pela falta de acesso à aquisição de terras baratas (pelo baixo poder de consumo da população de baixa renda).

Queremos aqui salientar que o investimento realizado pela prefeitura municipal foi de fundamental importância e que se vislumbrou para a população de mais baixa renda com condições de precariedade habitacional, em decorrência do alto valor dos imóveis uma maneira de obter uma qualidade de vida, através da garantia do direito a habitação. Pois, 
conforme a FetrafSul (2011) com subsídio do Governo federal, cada família assumiu parcelas de $10 \%$ da renda familiar, durante um período de dez anos, o que corresponde ao mínimo de $R \$ 50$ reais e ao máximo de $R \$ 139$ reais e 50 centavos/mês.

Entretanto, segundo Villaça (1998) um dos atributos mais representativos da segregação residencial na América Latina é os de ordem socioeconômicos. Ao traçar o perfil dos entrevistados, a grande parte deles é assegurada da Previdência Social que recebeu auxílio doença ou aposentadoria. A idade varia de 33 a 79 anos, com predominância para o sexo feminino, residentes no loteamento desde a criação, com predominância das famílias com até 3 membros, portanto famílias pequenas.

Além dos fatores socioeconômicos das classes, Marcuse (2004) aponta que contribui na segregação social e que reflete e reproduz as relações de poder e pode ser representada pela distribuição dos serviços públicos, pelo Estado. Os acessos diferenciados à infraestrutura urbana a equipamentos educacionais, de saúde e de lazer tornam-se a expressão materializada da atuação da sociedade na produção do espaço urbano.

O conjunto habitacional Expoente, possui pouca infraestrutura, não é considerado local de difícil acesso, foi apontado que necessita de manutenção, bem como as vias de acesso. No que se refere à iluminação pública tem, mas nos condomínios por falta de pagamento dos moradores é precária. No que tange a conservação do entorno do loteamento (estradas de acesso), existe um mato fechado o que se torna perigoso e causa medo para aqueles que precisam fazer o trajeto a pé.

Quanto aos equipamentos sociais, na área da saúde, os moradores utilizam a Policlínica do Bairro Seminário, bem como os demais equipamentos públicos e comerciais. As escolas ficam nas proximidades do Bairro, a maioria das crianças e adolescentes vão de ônibus para as escolas do município, segundo os moradores, para a escola São Francisco não existe ônibus e muitos vão a pé. A creche foi entregue ano passado.

No que se refere à área de lazer, existe apenas um campo de futebol, por causa disso ocorrem muitas brigas. Existe um quiosque na entrada do Loteamento 1, mas segundo os moradores, quem usa são os 'pias', chamados pelos moradores.

Para reunião e convivência existia um barracão, entretanto a 5 anos está depredado, sem condições de uso, interditado, além do mais está em péssimas condições, e que pode cair a qualquer momento, por causa disso, não tem lugar para reuniões de 
moradores, de acordo uma moradora, "a prefeitura disse que ia derrubar e construir outro, mas até agora nada. Ai nós não temos onde fazer reunião de morador" (Entrevistada 2).

A formação das cidades se dá sob a ordem que é fundamentalmente excludente do capitalismo. Esse sistema impõe as classes econômicas mais baixas a uma condição de subcidadania, afastadas das regiões importantes da cidade, onde é oferecida grande parte dos serviços públicos, do comércio e do lazer, limitando a sociabilidade e tornando o capital um gerador de segregação e de estigmatização de grupos sociais. Assim, ela se encontra em estreita relação com a produção e manutenção de preconceitos. (SCHMIDT, 2012).

As condições de vulnerabilidade social levam as famílias a sofrerem discriminação e preconceito, por residirem em um ambiente que carrega estigma, conforme evidencia as falas.

Minhas filhas deixaram currículo em várias empresas, não chamam, não conseguem emprego (Entrevistada 2).

As famílias não vem visitar a gente e as amizades não vem aqui por medo. [...]. (Entrevistada 3)

Taxi e pizzaria não adianta chamar que eles não vêm. Agora no seminário tem uma pizzaria que trás, mas só para quem ele conhece, já foram assaltados aqui (Entrevistada 4).

Eu tenho vergonha de dizer que moro no expoente, eu trabalhava para algumas empresas, que levavam a mercadoria aqui. Ai de repente disseram que não queriam mais meus serviços (Entrevistado 5)

Esses dias meu padrão queria me dar carona, eu não aceitei porque pensei, se ele me trazer vai saber onde eu moro, ele pensa que moro no Bairro Seminário. Eu trabalho lá a 4 anos, eles não sabem que moro aqui. [...]. ( Entrevistada 7).

Conforme Caldeira (2000) a violência e o medo combinam-se a processos de mudança social nas cidades contemporâneas, gerando novas formas de segregação espacial e discriminação social.

$\mathrm{Na}$ atualidade, a violência se acirra diante de uma sociedade globalizada, ainda fundada na exploração/dominação geradas pelo capitalismo, pelas relações de gênero patriarcais e pelo racismo (ROCHA, 2014). Outros exemplos são apresentados por Bonamigo e Chaves (2014), como as agressões contra pessoas em diferentes espaços; agressões específicas contra crianças, adolescentes e mulheres (incluindo as sexuais) no espaço familiar; violências no espaço da escola (agressões entre colegas e entre alunos e professores, presença de armas, ameaças, furtos e roubos relacionados ao patrimônio da 
escola); violências no trânsito (colisões e atropelamentos); violências contra o patrimônio (furtos e roubos de bens públicos e privados); tráfico e porte de drogas; porte de armas; sequestro-relâmpago; aplicação de pequenos golpes que implicam em extorsão financeira; preconceitos étnicos, homoafetivos, contra pessoas pobres, violência estatal (materializada na postura autoritária e no uso excessivo da força presentes nas ações públicas no campo da segurança), entre outras. O que nos faz observar o quão complexo é o fenômeno da violência.

No Loteamento Expoente, desde a entrada dos moradores, muitos acontecimentos de violência e criminalidade têm sido notícias dos jornais locais, problemática que levou muitas moradias serem vendidas ou abandonadas e que resultaram no dia 10 de abril de 2018, da primeira operação de reintegração de posse do período urbano de Chapecó e a primeira do MCMV do país.

Segundo o jornal Clic RDC (2018), em torno de 120 policiais envolvendo o Poder Judiciário, Polícia Militar, Polícia Civil, SaerFron, Polícia Federal, Batalhão de Choque, SAMU e Copo de Bombeiro, atuaram na reitegração de posse de 38 famílias em situação irregular no Loteamento Expoente.

A reintegração de posse foi ingressada pela Caixa Econômica Federal devido aos imóveis serem ocupados irregularmente por famílias, outros foram vendidos contra as normas do Programa Minha Casa Minha Vida, e invadidos por criminosos. E que por não ter havido a entrega consensual, houve a necessidade de expedição dos respectivos mandados de reintegração, conforme nota Divulgada pela Caixa (CLIC RDC, 2018).

Como a pesquisa de campo realizou-se logo depois deste acontecimento, muitos entrevistados, de uma forma direta comentaram o fato, relatando que muitas famílias não tinham recebido uma notificação. Simplesmente a operação foi realizada pegando todos desprevenidos. A operação causou indignação nos moradores e medo, pois relatos apontaram que alguns têm até medo de viajar, para visitar parentes e perder seu imóvel, mesmo estando regular nos pagamentos.

Caldeira (2000) adverte que o medo e violência, são difíceis de entender, fazem o discurso proliferar e circular. Todos os tipos de conversas, comentários, narrativas, que têm o crime e o medo como tema é contagiante. Quando se conta um caso, muito provavelmente vários outros se seguem. A fala do crime é também fragmentada e repetitiva. 
Ela surge no meio das mais variadas interações, repetindo a mesma história. Apesar das repetições, as pessoas nunca se cansam. Ao contrário, parecem compelidas a continuar falando sobre o crime, como se as infindáveis análises de casos pudessem ajudá-las a encontrar um meio de lidar com suas experiências inusitadas da violência. A repetição das histórias, no entanto, só serve para reforçar as sensações de perigo, insegurança e perturbação das pessoas. Assim, a fala do crime alimenta um círculo em que o medo é trabalhado e reproduzido, e no qual a violência é a um só tempo combatida e ampliada.

As violências se intensificam na visão de Sodré (2003) pelo processo de urbanização manifestadas através de vandalismos, delinquência, marginalidade, crimes de mortes, assaltos que são decorrentes da violência exclusiva da ordem social.

Apesar de todas as pessoas entrevistadas estarem preocupadas com a violência, a maioria delas já havia sofrido algum tipo de violência, direta ou indiretamente (um amigo, um parente ou alguém próximo a elas já tinha sido vítima). Os crimes contra a propriedade, sobretudo arrombamento e furto de residências. Os crimes contra pessoas, inclusive assassinato, foram três, e agressões físicas e verbais; o consumo e a venda de drogas. Nem todos, tinha sido vítima direta do crime violento, mas tinha testemunhado uma grande violência no Loteamento ou entre pessoas que conheciam.

Os crimes que relataram tinham ocorrido em diferentes lugares: nas ruas, em suas casas através de relatos de vários episódios de assalto e depredação as residências, na proximidade de suas casas, no entorno do Loteamento, no transporte público, nos espaços de convivência e de lazer.

Os jovens, chamados pelos moradores de "pias" são considerados socialmente marginais, e seus comportamentos são condenados, relataram que usam palavrões, são 'sem vergonha', consomem drogas e assim por diante. De certo modo, explica Caldeira (2002, p.80) "tudo o que quebra os padrões do que se considera boa conduta pode ser associado a criminosos, ao crime e a seus espaços". Ou seja, o que pertence ao crime é tudo o que a sociedade considera impróprio.

Com o crescimento dos índices de violência amplia-se o medo e a sensação de insegurança no cidadão comum. Bauman (2009, p.10) afirma que a “[...] a insegurança moderna, em suas várias manifestações, é caracterizada pelo medo dos crimes e dos 
criminosos". Nessa ótica, a insegurança aumenta o medo, e a população acredita e reafirma quando perguntado,

Eles ficam soltos e nós temos que nos trancar, ficar presos em casa e colocar grade na porta, mesmo assim eles podem vir com alguma ferramenta, abrir e atirar na gente (Entrevistado 1).

Algo que nos chamou a atenção, nas casas visitadas, foi a pouca sociabilidade local, os moradores confirmam que o Loteamento não é seguro, o que levou a fortificarem suas casas, por medo do crime, suas portas estavam fechadas, protegidas por grades, mesmo nos apartamentos, cada andar era protegido por grades, barras nas janelas por estarem mais desconfiadas, falam com estranhos na rua por detrás de grades, escolhem com cuidado as pessoas que vão se relacionar e controlam seus filhos para não brincarem nas ruas e para utilizarem o espaço público o menos possível.

Os "enclaves fortificados" de acordo com Caldeira (2000) tornou-se um elemento central de um novo e já difundido padrão de segregação urbana baseado em enclaves fortificados. Trata-se de espaços privatizados, fechados e monitorados para residência, consumo, lazer e trabalho. Os condomínios fechados, é o novo tipo de moradia fortificada da elite, não são lugares para os quais as pessoas caminhem ou pelos quais passem. São fisicamente demarcados e isolados por muros, grades, espaços vazios e detalhes arquitetônicos. São essenciais na cidade de hoje, por razões de segurança e segregação, mas também por questões estéticas e de status. Embora tendam a serem espaços para as classes altas, podem ser situados em áreas rurais ou na periferia, ao lado de favelas ou casas autoconstruídas. São claramente demarcados por todos os tipos de barreiras físicas e artifícios de distanciamento e sua presença no espaço da cidade é uma evidente afirmação de diferenciação social. Eles oferecem uma nova maneira de estabelecer fronteiras entre grupos sociais, criando novas hierarquias entre eles e, organizando explicitamente as diferenças como desigualdade. Houve uma ampliação dos condomínios a partir dos anos 70 para as classes dos trabalhadores, entretanto existem aqueles empreendimentos mais sofisticados e caros para a população da classe alta. A diferença dos antigos condomínios é o isolamento, com espaços fechados, bem seguros, com espaços comuns, áreas de circulação, pleigraouds e salões de festas. O que diferencia os "enclaves fortificados" da classe alta com o da população empobrecida são a segurança e a urbanização ofertada pelo Estado. 
Enquanto, o primeiro gasta grandes valores com segurança, os condomínios de Habitação Social são de $42 \mathrm{~m} 2$, longes da cidade, sem transporte público de qualidade, sem infraestrutura urbana, e necessitam da proteção pessoal, suas casas são padronizadas, e desavalorizadas pela população em geral como também por aquelas que não tem outra opção a não ser viver nelas.

A insegurança leva a população a desaparecer das ruas. A ficarem trancados em casa, e só saírem para quando for necessário, muitas moradores relataram não saírem muito de casa, para não se incomodarem. Uma mãe relatou,

Medo de deixar a sua filha ir ao supermercado. Parece que o problema maior é quando somos mulher e moramos só com filhas. Quanto tem um homem na casa, mesmo menor de idade parece que eles respeitam mais. Porque sabem que se eles falaram alguma coisa pra mãe deles, vai tomar uma atitude (Entrevistada 4).

Nessa fala, e conforme o sexo das entrevistadas (o), a maioria do sexo feminino, observa-se que a maioria é composta de família monoparental, tendo como provedora a mulher. Saffiotti (1979) mostra que a história da instituição familiar sempre teve como ponto de partida o modelo patriarcal, importado pela colonização e adaptado às condições do Brasil da época, latifundiário e escravista. Entretanto, essa hegemonia é questionada, haja vista a pluralidade de famílias brasileiras de origem africana, indígena e das classes populares como um todo, como famílias columbinas, chefiadas por mulheres com seus filhos, e os adotivos.

Com as transformações do final do século XIX e início do XX instituem um novo modelo de família no Brasil, que se opunha ao modelo patriarcal. E a famílias monoparentais femininas, ou chefiadas por mulheres, com a presença o cônjuge ou não cresce. Nesse modelo, Teixeira (2013) constata que a mulher na condição de provedora do lar, enfrenta maiores dificuldades, tendo em vista as desigualdades de gênero que atravessam o mercado, os salários e as condições de trabalho, e a responsabilização destas sozinhas, de cuidar, proteger os filhos.

Portanto, o fenômeno da violência, se torna um dos grandes desafios da atualidade, pois enquanto recorte do social, na visão de Silva (2005) perpassa o cotidiano de todos de forma atordoante, sendo necessário buscar novos parâmetros para sua compreensão e enfrentamento. A violência possui ligações profundas com a desigualdade entre as classes e 
a exclusão social, dessa forma, seu enfrentamento não pode eximir-se da melhoria do sistema de proteção social, do fortalecimento das políticas sociais e da garantia de direitos.

Não queremos confirmar a partir do perfil das famílias entrevistadas e ou reforçar, que a pobreza gera violência, a cargo de (Ziccardi, 2016) mostrar que as expressões da questão social que vive a grande parte da população e a questão urbana são marcadas pelas condições de precariedade do trabalho e enfraquecimento do modelo do Estado de BemEstar, bem como a persistência e aumento da pobreza urbana que deu origem aos processos de urbanização da pobreza e à ampliação das desigualdades econômico, social e territorial. Neste contexto, a questão urbana se expressa nas cidades do século XXI, como espaços fragmentados e divididos ou segmentados, características que, embora as cidades da América Latina sempre tiveram, agora foram amplificados. Percebe a autora, que a pobreza urbana é uma consequência da precariedade, da informalidade e, sobretudo, dos baixos salários que recebem milhões de trabalhadores. A situação social e urbana, entretanto, não afeta apenas esses cidadãos que têm poucas possibilidades de exercer seus direitos sociais, mas para toda a sociedade, fraturando o tecido social e gerando condições favoráveis à proliferação da violência e insegurança.

\subsection{Segurança Publica: proteção ou punição?}

De acordo com Caldeira (2000), o Brasil é hoje uma democracia em que os direitos políticos e a liberdade de organização e de expressão são amplamente garantidos. Os principais alvos da violência policial não são adversários políticos, mas sim aqueles considerados "suspeitos" (supostos criminosos), em sua maioria, pobres e desproporcionalmente negros. Isso ocorre por causa do apoio popular a essa violência, as violações dos direitos humanos são uma questão pública, exibidas diariamente pelos meios de comunicação de massa, livres de censura. No entanto, muitas vezes os abusos são apoiados por uma população que classifica direitos humanos como "privilégios de bandidos".

Ao discorrer acerca da segurança pública nos reportamos à análise de Bonamigo e Chaves (2014), que buscam sua fundamentação em Rousseau. Para os autores a segurança pública é uma criação social nascida no bojo da passagem de estágio da convivência natural ao 
da convivência social. É nesse processo social que homens e mulheres abrem mão de alguns direitos naturais, delegando-os a uma instância superior, responsável pela segurança coletiva.

Entretanto, a política da segurança pública desde sua gênese, mesmo socialmente fundamental, em todos os regimes políticos foi mantida como um campo de menor prioridade, tratada em uma ótica militarista, com o uso predominante da violência com forma de dominação. Mesmo com os esforços da última década e os importantes movimentos de introdução de conteúdos de direitos humanos e formação humana nas academias militares estaduais e civis, mantém-se a lógica tradicional de uso da violência institucional (BONAMIGO e CHAVES, 2014).

Nessa ótica, os entrevistados, experienciam a violência diariamente, tanto por parte de criminosos como da polícia, que as transformou em seu alvo principal. Em consequência, os moradores não confiam na polícia e dificilmente têm uma visão positiva dela. Na maior parte dos casos, eles têm medo da polícia, e com razão, pois, percebeu-se algumas práticas violentas da própria polícia as quais produzem medo e insegurança "onde todos são suspeitos",

Aqui também já vimos policiais arrastarem um piá até a esquina. Bateram nele, depois arrastaram. As vezes chegam no ponto de ônibus e começam a bater em quem está lá, se é piazada, sem saber se são culpados ou não. Quando eles vinham aqui, as pessoas que estavam na rua, na frente das casas, não podia olhar para a polícia, porque eles diziam que iam bate (Entrevistada 4).

A polícia criou inimigo aqui, porque elas viram seus filhos apanharem e já falaram aqui é tudo bandido mesmo. Mas somos pessoas trabalhadoras, os filhos estudam, outros fazem faculdade, mas todos somos vistos como bandidos (Entrevistada 9).

Para os moradores, a polícia já foi bem mais violenta, no ultimo ano parece que isso mudou, "no início, os pia fugiam da polícia, corriam por medo, porque eles batiam antes para depois perguntar. Pisavam na cabeça. Depois foram conhecendo o lugar e vendo que não são todos bandidos, aqui tem trabalhador". (Entrevistado 5).

Para Marino (2017, p.3) a polícia representa uma das principais instituições de uma cidade.

Encarregada pela imposição da ordem, as forças policiais alicerçam uma estrutura vinculada aos interesses estatais e, consequentemente, aos interesses sociais hegemônicos. [...], ao focarmos nossa análise nas forças policiais pretendemos colocar em apreciação uma instituição construída ao longo de mais de dois séculos, que se mostra reticente a mudanças. 
Na visão dos moradores, a Polícia Civil e Militar não tem autoridade na comunidade. Eles chegam lá e são chamados de "rato, porco, verme" (Entrevistada 2). Já a Polícia Tática é mais respeitada, "eles chegam aqui e quebram a pau quem eles pegam, chegam armados, com muitos carros, com spray de pimenta..." (Entrevistada 4).

A crítica contra a polícia é bastante visível, mas temos que levar em consideração os perigos enfrentados pelos policiais e suas más condições de trabalho, o que não justifica a violência praticada.

Em situações de violência, os moradores sentem-se impotentes. Ficam paralisados entre o medo da polícia, o medo da vingança do criminoso. Sem proteção, adotam o silêncio como uma maneira de manter boas relações com criminosos moradores do Loteamento. Segundo alguns relatos, correram boatos de que os traficantes possuem acesso ao radio amador da polícia, e ficam sabendo quem está denunciando, e podem sofrer represálias dos traficantes. Ou então, quando a população chama a polícia, precisam se identificar o que também acarreta medo de denunciar. A polícia não dá segurança pra gente. Se ligar para a polícia, eles querem saber
quem é que tá falando, ai a gente fica com medo, então não ligamos
(Entrevistado 7)

Nesse aspecto de segurança, Caldeira (2000) faz uma análise interessante, ao mencionar que o Poder Judiciário está longe de ser visto como confiável, e que também faz parte do controle do crime, pois o universo do crime parece incluir apenas criminosos, policiais e cidadãos impotentes, que têm de negociar sua segurança por conta própria e entre si.

Sentimentos de medo e vulnerabilidade em relação à polícia fazem com que os moradores sintam-se pressionadas contra a parede. Por um lado elas defenderam a força contra supostos criminosos e por outro justificam e desejam a presença da polícia. Uma das moradoras relata, "se tivesse um posto aqui, muita coisa não teria acontecido, muitas mães não teriam perdido seus filhos para as drogas e para o crime". (Entrevistada 2). As entrevistadas 4 e 9 relatam,

Se todas as promessas feitas, tivessem sido cumpridas, seria um loteamento exemplar, se tivesse posto de polícia, teriam apoio da população, ia inibir os adolescentes se envolver com drogas, a depredação das casas e apartamentos e as mortes (Entrevistada 4). 
Se tivesse uma base policial aqui teria mais segurança. Não teria acontecido tantas mortes, teria tido mais prisões, e pessoas não teriam saído daqui por medo (Entrevistada 9).

Portanto, a solução da criminalidade, vem da própria comunidade, no caso, indicam a presença efetiva do Estado na região para garantir a plena realização dos direitos de cidadania, a partir da construção de um posto policial. Que segundo eles isso foi prometido, mas não cumprido até hoje, 7 anos depois da entrega do Loteamento.

Parece fora de duvida que isso, conforme Silva (2009) se restringe ao tratamento dos problemas (no caso, a segurança publica) a uma guerra contra atividades que perturbam os aspectos interpessoais mais rotineiros da vida social. E que atribui a culpa a um segmento, os moradores dos territórios da pobreza a partir de sua criminalização indiscriminada, tornam-se o tipo ideal do outro que precisa ser afastado a qualquer preço. Em decorrência, convergem para os aparelhos policiais todas as atenções e demandas de recomposição da ordem social. Cresce o clamor por uma ação "dura", única possibilidade de evitar a contaminação de todo o quadro mais geral do conflito social institucionalizado. Completa o autor, que este é o segredo, praticado, mas não tematizado, do aumento conjugado de democratização e expansão da violência. O dispositivo fundamental que faz a mediação e a delegação de grandes parcelas da sociedade para que as corporações tomem decisões, segundo critérios próprios, sobre o uso da forca e a definição dos inimigos a combater, reais ou imaginários.

\section{Considerações finais}

A pesquisa mostrou que a violência é um fenômeno bastante grave no "Loteamento Expoente", o que demonstra que o direito à habitação, enquanto realização de um sonho se tornou um grande pesadelo. Haja vista, que todos relataram as diversas formas de violência sofrida diretamente ou indiretamente.

As violências sofridas e percebidas são multifacetadas. Além da falta de garantia dos direitos básicos de cidadania como direito de ir e vir, existem outras formas de violação de direitos que reproduzem os fenômenos criminais. Como forma de coibir a criminalidade e a violência, a comunidade justifica e deseja a presença da polícia. Nessa ótica, o medo de ser 
vítima assusta muito a comunidade, o que acaba acarretando aumento da pressão pela adoção de medidas mais duras contra os criminosos.

A pesquisa revelou a existência dos problemas da violência e da criminalidade enfrentados pelos moradores do empreendimento habitacional em questão. Entretanto, observa-se que o território em que está o Loteamento Expoente é uma comunidade com grande número populacional, empobrecidas, com diferentes grupos e de idades diversificadas, com ausência de ambientes adequados às necessidades das famílias, em função da execução de projetos que não contemplam a realidade, bem como ausência de relações entre vizinhos, e de intergeracionais, onde muitos dos jovens e adultos estão envolvidos com o tráfico de drogas. A falta de pertencimento ao lugar a nosso ver, contribui para a marginalização e da depredação da estrutura do Loteamento.

Foi possível concluir que o direito à cidade está atrelado a uma economia mundial que hegemonicamente é capitalista e neoliberal, que intensificou a pobreza urbana pelas transformações advindas do mundo do trabalho. A proliferação da violência e da insegurança é fruto destas condições desfavoráveis em que se encontra grande parte da população. A política pública ofertada ao contingente de pessoas que vivem na pobreza, na especificidade da política de habitação social, vai além do direito a uma casa, mas inclui a efetivação do desenvolvimento social, econômico e cultural de seus moradores.

\section{Referências}

ARAGÃO, Thêmis Amorim. A Produção social da moradia e o Programa Minha Casa Minha Vida. In: FERREIRA, Regina Fátima C. F.; BIASOTTO, Rosane Coreixas (Orgs.). Políticas públicas e direito à cidade: Política Habitacional e o direito à moradia digna: programa interdisciplinar de formação de agentes sociais e conselheiros municipais. Caderno didático. Rio de Janeiro: Letra Capital, 2012.

BARDIN, Laurence. Análise de Conteúdo. Edição revista e ampliada. São Paulo: edições 70, 2011.

BARROS, Aidil de Jesus Paes de.; LEHFELD, Neide Aparecida de Souza. Projeto de pesquisa: proposta metodológicas. 1 ed. Revista e atualizada. Petrópolis, RJ: Vozes, 1990.

BAUMAN, Zygmunt. Confiança e medo na cidade. Rio de Janeiro: Jorge Zagar Ed., 2009. 
BONAMIGO, Irme Salete; CHAVES, Luiz Carlos. Poder, violências e política no campo da segurança pública. Revista de Políticas Públicas, São Luís, v. 18, n. 2, p. 457-470, jul./dez. 2014. Disponível em: <http://www.periodicoseletronicos.ufma.br/index.php/rppublica/ article/view/3173/1263>. Acesso em: 15 jul. 2018.

CALDEIRA, T. P. Cidade de Muros: crime, segregação e cidadania em São Paulo. São Paulo: 34/Edusp. 2000.

CASTEL, Robert. Les métamorphoses de la question sociale. Paris: Fayard, 1995.

CLICRDC. PM cumpre 38 mandados de reintegração de posse no loteamento expoente. 2018. Disponível em: https://clicrdc.com.br/pm-cumpre-38-mandados-de-reintegracao-deposse-no-loteamento-expoente/. Acesso em: 21 mai. 2018.

FETRAFSUL. Loteamento Expoente. Disponível em:

http://www.fetrafsul.org.br/siteantigo/index.php?option=com_content\&view=article\&id=96 9:Ioteamento-expoente\&catid=1:ultimas-noticias\&ltemid=104. Acesso em 25 abr. de 2018.

FLICK, Uwe. Introdução à pesquisa qualitativa. 3 ed. Porto Alegre: Artmed, 2009.

HARVEY, D. $O$ direito à cidade. Lutas sociais. São Paulo, n.29, p.73-89, jul a dez 2012. Disponível em: http://www4.pucsp.br/neils/downloads/neils-revista-29-port/davidharvey.pdf. Acesso em: 30/04/2017.

HERTZEL, Daiana. Conjunto habitacional de interesse social: garantia de direitos ou produção de segregação socioespacial? 2016. 80 f. Dissertação (Mestrado em Ciências ambientais) - Universidade Comunitária da região de Chapeco, Chapecó, 2016.

IAMAMOTO, Marilda. A Questão Social no Capitalismo. Revista Temporalis, Brasília: ABEPSS, $n \div$ 3, 2001.

LEFEBVRE, Henri. O direito à cidade. Tradução. Rubens Eduardo Frias. São Paulo: Centauro, 2001.

MARICATO, Ermínia. O Ministério das Cidades e a Política Nacional de desenvolvimento urbano. Políticas Sociais: acompanhamento e análise. São Paulo: IPEA, fev. 2006.

. Por um novo enfoque teórico na pesquisa sobre habitação. Cadernos metrópole 21 pp. 33-52 $1^{0}$ sem. 2009.

MARINO, Leonardo. Geografia e poder: o ordenamento territorial da cidade do Rio de Janeiro e a genealogia da violência policial no Brasil. Revista bibliográfica de Geografía y Ciencias Sociales. Universidad de Barcelona ISSN: 1138-9796 Depósito Legal: B. 21.742-98 Vol. XXII, núm. 1.2135 de octubre de 2017. Disponível em:

file:///C:/Users/Usuario/Downloads/Geografia_e_poder_o_ordenamento_territor\%20(1).pd f Acesso em: 24 abr. 2018. 
MARCUSE, Peter. Enclaves, sim; guetos, não: a segregação e o estado. In: Espaço e Debates. São Paulo: NERU. v. 24, n. 45, jan./jul. 2004, pp. 24-33.

MARX, K. e ENGELS, F. Lei geral da acumulação capitalista. O Capital, Vol II. Os economistas. São Paulo: Nova Cultura, 1985.

MEDEIROS, A. K. S. de. Exclusão social e projetos habitacionais: um estudo sobre conjuntos habitacionais, segregação e exclusão social em Natal. 2013, f.159. Dissertação (Mestrado) Arquitetura e Urbanismo - Universidade Federal do Rio Grande do Norte, 2013.

MINISTÉRIO DAS CIDADES. Secretaria Nacional de Habitação. PlanHab. Produto 5. Brasília: Ministério das Cidades/ Secretaria Nacional de Habitação, 2009.

ROCHA, Lourdes de Maria Leitão Nunes. Dossiê: poder, violência e políticas públicas no contexto contemporâneo. Revista de Políticas Publicas. v.18, n.2,p.339-342, jul/dez, 2014. Disponível em:

http://www.periodicoseletronicos.ufma.br/index.php/rppublica/article/view/3178/3940. Acesso em 10 jul. 2018.

ROLNIK, R. Guerra dos lugares: a colonização da terra e da moradia na era das finanças. 1 ed. São Paulo: Bointempo, 2015.

SAFFIOTI, H.I.B. A Mulher na Sociedade de Classes: Mito e Realidade. Petrópolis, Ed. Vozes, Rio de Janeiro, 1979.

SILVA, Sueli Baptista da. O Serviço Social frente à questão da violência doméstica: a realidade social revelada nas ações judiciais da Vara da Infância, da Juventude e do Idoso da Comarca da Capital do Rio de Janeiro. 2005. Dissertação (Mestrado) - Departamento de Serviço Social PUC-Rio, 2005. Disponível em: https://www.maxwell.vrac.pucrio.br/Busca_etds.php?strSecao=resultado\&nrSeq=8735@1. Acesso em: 10 jul. 2018.

SILVA, Luiz Antonio Machado da. Polícia e segurança pública no Rio de Janeiro de hoje: Uma tomada de posição. In: OLIVEIRA, Kris Brettas; OLIVEIRA, Gleiber Gomes de. (Orgs.). Olhares sobre a prevenção à criminalidade. Belo Horizonte: Instituto Elo, 2009.

SCHMIDT, Naiara Conservani. Cidades médias: segregação e as novas formas de sociabilidade. In: III EICS, 2012, Pelotas. Crise e Emergência de Novas Dinâmicas Sociais.

SODRÉ Muniz. Violência, mídia e política. In: FEGHALI, Jandira; MENDES, Cândido; LEMGRUBER, Julieta (Orgs.). Reflexões sobre violência urbana: (in) segurança e (des) esperaça. Rio de Janeiro: Prevenção e ação, 2003. Disponível em: https://books.google.com.br/books?id=TeN-07sG0cUC\&pg=PA33\&lpg= PA33\&dq=sodr\%C3\%A9+a+viol\%C3\%AAncia+urbana\&source=bl\&ots=CHrntFW_3Q\&sig=wW ku8DMBi_XINrxPI_Au0azyH9s\&hl=pt-BR\&sa=X\&ved=0ahUKEwj_c70lpXbAhUFEpAKHXKBvUQ6AEIWTAF\#v=onepage\&q=sodr\%C3\%A9\%20a\%20viol\%C3\%AAncia\%20urbana\&f=false. Acesso em: 12 jul. 2018. 
TEIXEIRA, Solange Maria. Família e proteção social: uma relação continuamente (re) atualizada. In: . A família na política de Assistência Social: concepções e as tendências do trabalho social com família no CRAS de Teresina-PI. Teresina: EDUFPI, 2013.

TORRES, Haroldo da Gama; et al. Pobreza e espaço: padrões de segregação em São Paulo. Estudos Avançados, v. vol.17 n.47 São Paulo Jan./Apr. 2003. Disponível em: http://www.scielo.br/scielo.php?script=sci_arttext\&pid=S0103-40142003000100006. Acesso em 20 jul. 2018.

ZICCARDI, Alicia. Cuestión social y el derecho a la ciudad. In: CARRIÓN, Fernando; ERAZO, Jaime. (Coord.). El derecho a la ciudad en América Latina Visiones desde la política. 1ed. México: Universidad Nacional Autónoma de México, 2016.

VILLAÇA. F. Espaço Intra-Urbano no Brasil. São Paulo: Studio Nobel, 1998. 